\title{
Late Blight Resistance Screening of Major Wild Swedish Solanum Species: S. dulcamara, S. nigrum, and S. physalifolium
}

\author{
Kibrom B. Abreha, Åsa Lankinen, Laura Masini, Sofia Hydbom, and Erik Andreasson ${ }^{\dagger}$
}

Department of Plant Protection biology, Swedish University of Agricultural Sciences, Box 102, 23073 Alnarp, Sweden. Accepted for publication 9 January 2018.

\begin{abstract}
To understand the contribution of wild Solanum species to the epidemiology of potato late blight in Sweden, we characterized the resistance of the three putative alternative hosts: S. physalifolium, S. nigrum, and S. dulcamara to Phytophthora infestans, the causal agent of late blight. The pathogen sporulated in all 10 investigated $S$. physalifolium genotypes, suggesting susceptibility (S phenotype). Field-grown S. physalifolium was naturally infected but could regrow, though highly infected genotypes were smaller at the end of the season. In 75 S. nigrum genotypes, there were no symptoms ( $\mathrm{R}$ phenotype) or a lesion restricted to the point of inoculation $\left(\mathrm{R}^{\mathrm{N}}\right.$ phenotype), indicating resistance. In

164 S. dulcamara genotypes, most resistance variability was found within sibling groups. In addition to the three resistance phenotypes $\left(R, R^{N}\right.$, and $\mathrm{S})$, in S. dulcamara a fourth new resistance phenotype $\left(\mathrm{S}^{\mathrm{L}}\right)$ was identified with lesions larger than the point of inoculation but without visible sporulation of the pathogen. Quantitative PCR confirmed P. infestans growth difference in $\mathrm{R}^{\mathrm{N}}, \mathrm{S}^{\mathrm{L}}$, and $\mathrm{S}$ phenotypes. Thus, in Sweden S. physalifolium is susceptible and could be a player in epidemiology. A limited role of $S$. dulcamara leaves in the epidemiology of late blight was suggested, since no major symptoms have been found in the field.
\end{abstract}

Potato (Solanum tuberosum) is the third most important food crop grown worldwide. Most cultivars of potato are, however, susceptible to Phytophthora infestans, which causes the late blight disease. Despite extensive research, $P$. infestans still devastates potato production, causing an estimated financial loss of more than $€ 5$ billion per annum worldwide (Haverkort et al. 2009). Developing potato cultivars resistant to $P$. infestans, e.g., by exploiting natural host resistance in wild Solanum species, is a common method of late blight control. The use of $P$. infestans-resistant cultivars in Sweden alone could save up to $€ 10$ million per annum (Eriksson et al. 2016). However, the rapid rate of change in $P$. infestans to overcome resistance (Haas et al. 2009) makes it necessary to have many different resistance sources.

Determining resistance to $P$. infestans of genotypes of wild Solanum species can provide new resistance sources in potato breeding (Rodewald and Trognitz 2013). Studying the resistance in wild Solanum species growing in close proximity to potato fields can also help understand the epidemiology of the pathogen. As wild hosts are generally more diverse in resistance mechanisms than cultivated crops, even small numbers of wild hosts can have a large impact on the pathogenic variation (Burdon and Thrall 2008). Such knowledge could potentially help in the design of alternative control measures for potato cultivation (Zhan et al. 2015). For example, removal of wild $S$. dulcamara, an alternative host of Ralstonia solanacearum that causes brown rot disease in potato (Elphinstone et al. 1998; Wenneker et al. 1999), was used for successfully eradicating $R$. solanacearum in southern Sweden in the 1970 s (Persson 1998).

${ }^{\dagger}$ Corresponding author: E. Andreasson; E-mail: erik.andreasson@slu.se

This work was funded by the Swedish Foundation for Strategic Environmental Research (Mistra), The Swedish Research Council for Environment, Agricultural Sciences and Spatial Planning (FORMAS), and Swedish University of Agricultural Sciences (SLU).

*The $\boldsymbol{e}$-Xtra logo stands for "electronic extra" and indicates that four supplementary figures and one supplementary table are published online.

C 2018 The American Phytopathological Society
Almost all the wild Solanum species used in potato breeding are from South America (Rodewald and Trognitz 2013), while the variation in resistance to $P$. infestans in the wild Solanum gene pool from Europe remains poorly characterized. This is significant because the Phytophthora populations that challenge the wild Solanum species found in Europe could be different from those challenging the South American species. As a result, the wild species from Europe might provide a new sources of resistance against the pathogen. In Sweden, there is high local variation within the $P$. infestans population (Yuen and Andersson 2013) that might be reflected in diverse resistance mechanisms in the wild Solanum species growing in the area (Burdon and Thrall 2008). It would therefore be of particular interest to explore resistance of wild Solanum growing in the agricultural landscape in Sweden.

Three species constitute the major wild Solanum spp. in Sweden, S. dulcamara (bittersweet), S. nigrum (black nightshade), and S. physalifolium (hairy nightshade) (Mossberg and Stenberg 2003). Both $S$. dulcamara and S. nigrum are considered native to Europe, whereas $S$. physalifolium was introduced from South America. S. dulcamara $(2 n=2 x=24)$ is a perennial and outcrossing species that grows in diverse habitats, sometimes in the direct vicinity of potato fields (Dawood et al. 2014; Golas et al. 2010a). A resistance screening of $90 \mathrm{~S}$. dulcamara genotypes, collected from more than 12 countries in Europe (excluding Sweden), revealed that most genotypes were resistant but susceptible genotypes were occasionally found (Golas et al. 2010b). S. nigrum (di-, tetra-, or hexaploid) and $S$. physalifolium $(2 n=2 x=24)$ are annual and self-pollinating weeds occurring in agricultural fields with open soil (including potato fields) and in ruderal areas. S. nigrum has been recognized as a nonhost species to $P$. infestans (Colon et al. 1992; Vleeshouwers et al. 2000). However, strains of the pathogen that can infect $S$. nigrum have been identified in Poland (Lebecka 2008) and the Netherlands (Flier et al. 2003). In contrast, S. physalifolium can be highly susceptible to $P$. infestans (Andersson et al. 2003; Gronberg et al. 2012; Lankinen et al. 2016). Previous studies of wild Solanum species from Sweden have used only a limited number of genotypes (Frades et al. 2015; Lebecka 2008), hence it is difficult to make general inferences about the resistance to P. infestans of the wild populations in Sweden. 
In Solanum species, three resistance phenotypes against $P$. infestans have been described: $\mathrm{R}$, resistance without any visible infection symptoms; $\mathrm{R}^{\mathrm{N}}$, resistance with visible necrosis equal to or smaller in size than the area of the inoculation with no sporulation; and S, susceptible with sporulating lesions (Lebecka 2008). Plant defense responses to pathogen attack can also be influenced by environmental conditions (Fukuoka et al. 2015; MacQueen and Bergelson 2016). For example, leaves collected from field-grown and greenhouse-grown plants of the same $S$. nigrum genotype showed a different resistance level against one strain of $P$. infestans (Lebecka 2008). Similarly, clones of S. tuberosum showed differential responses to $P$. infestans inoculation when grown in greenhouse, field, or laboratory condition (Sharma et al. 2013). Moreover, (Rietman et al. 2012) reported that a multigene-related resistance against $P$. infestans could only be detected under field conditions. Therefore, it is important that resistance-screening experiments are conducted on both controlled- and field-grown genotypes. Additionally, to get an indication of the potential influence of the wild Solanum species on disease epidemiology, it is informative to learn about how performance traits of plant genotypes are interrelated with infection or resistance responses, e.g., suggested fitness costs of resistance (Brown and Tellier 2011).

In this study, our overall aim was to investigate resistance variation to $P$. infestans in the major wild Solanum species found in the agricultural area of southern Sweden, and to determine their likely impact on disease epidemiology. Seeds from wild populations were collected and the resistance of 10 genotypes of $S$. physalifolium, 75 genotypes of $S$. nigrum, and 164 genotypes of $S$. dulcamara were screened using quantitative and qualitative measurements from detached leaf assays on chamber- and field-grown genotypes. A new classification of the pathogen response in the genotypes was confirmed by quantitative PCR of the pathogen. In the species with detected susceptible genotypes, $S$. physalifolium and S. dulcamara, performance parameters were also assessed in relation to natural infection (in S. physalifolium) or resistance phenotypes in detached leaf assays (in $S$. dulcamara) to investigate the fitness cost of the infection or of the resistance. The objectives of this study were to (i) identify different resistance phenotypes and investigate the variation in resistance within and among the wild Solanum species, (ii) study how much of the resistance variation in S. dulcamara is distributed within populations, or within sibling groups, and (iii) determine how performance parameters in S. physalifolium and $S$. dulcamara are related to natural infection or to resistance against $P$. infestans.

\section{MATERIALS AND METHODS}

Plant material and propagation. S. physalifolium, S. nigrum, and $S$. dulcamara seeds were collected from plants growing in natural habitats in southern Sweden in 2010 and 2011 (Supplementary Fig. S1). Henceforth in this report, each collection site represents one population of the wild species. The area from which the plant populations were collected varied in size from a few square meters to ca. $100 \mathrm{~m}^{2}$. Plant material was collected as seeds from three to 10 plants per population and 5 to 10 berries per plant. Seeds were extracted from the berries of an individual plant, the offspring of which is further referred to as sibling group. Seed germination and growing of plants in the growth chambers were performed as described previously (Bengtsson et al. 2014b; Lankinen et al. 2016).

Resistance screening. Resistance screening experiments, using a detached leaf assay (Ali et al. 2012), were performed between 2012 and 2014 on genotypes grown in growth chambers $(65 \% \mathrm{RH}, 16 \mathrm{~h}$ light and $22^{\circ} \mathrm{C}$ ) and in an experimental garden located at the Swedish University of Agricultural Sciences, Alnarp campus $\left(55^{\circ} 66^{\prime} \mathrm{N}\right.$, $13^{\circ} 08^{\prime} \mathrm{E}$ ) (Fig. 1). Accordingly, five leaves per genotype were detached and a $20-\mu l$ droplet of a $P$. infestans suspension $(15,000$ sporangia/ml), harvested from detached leaves of susceptible potato cultivar Désirée, was placed on the abaxial side of the detached leaves. To ensure the efficacy of the inoculum, the susceptible potato cultivar Désirée was included as a positive control in each assay. $P$. infestans strain SE-03058 (virulence 1, 3, 4, 7, 10, and 11) (Ali et al. 2012; Moushib et al. 2013), isolated in southern Sweden, was used in all assays.

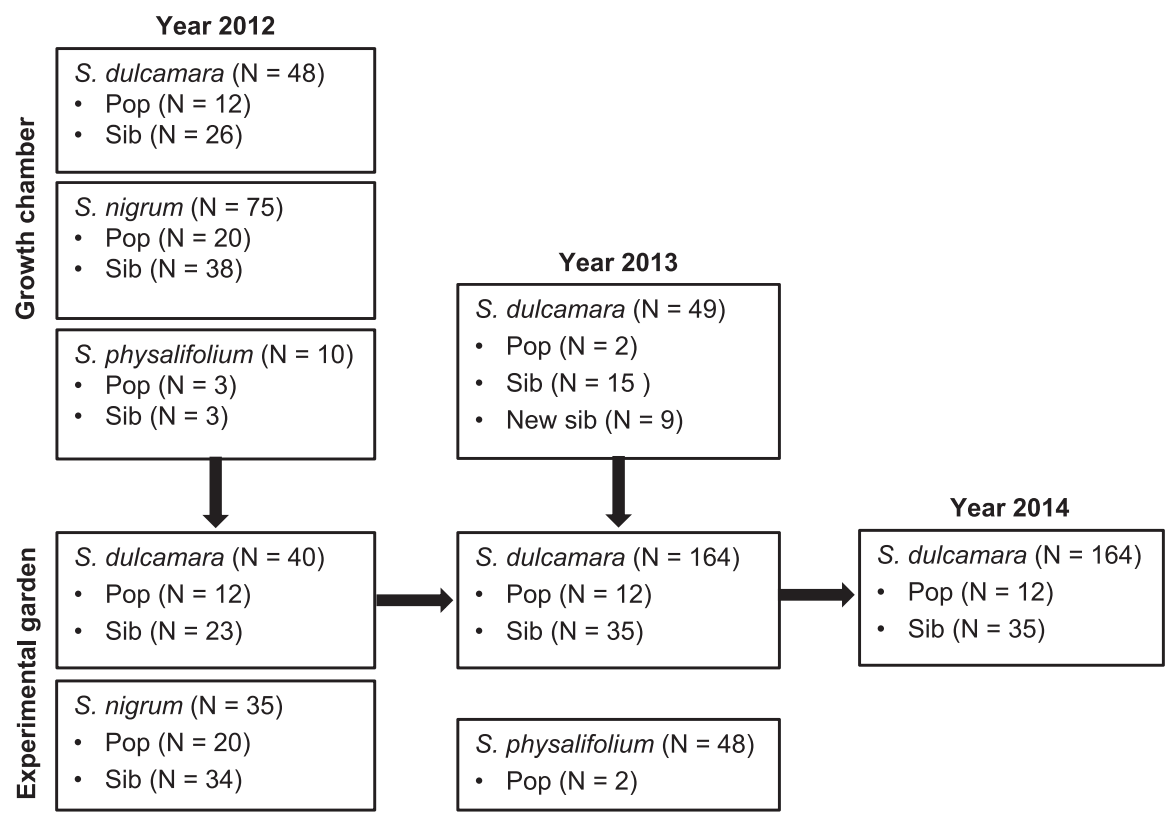

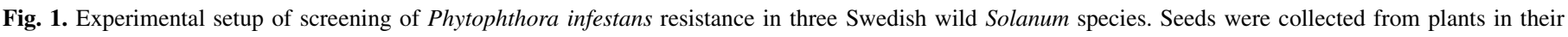

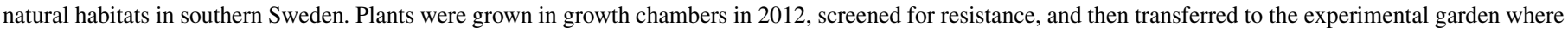

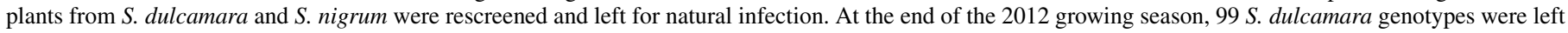

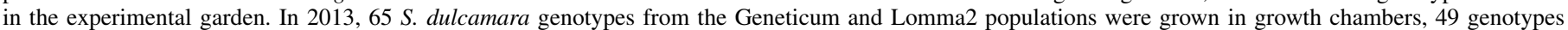

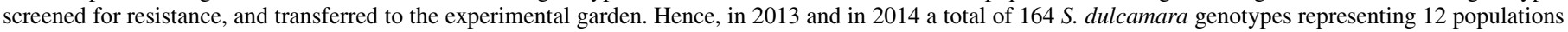

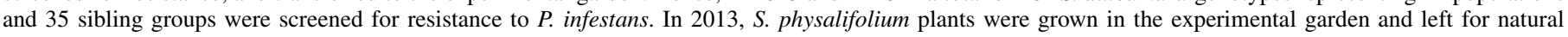

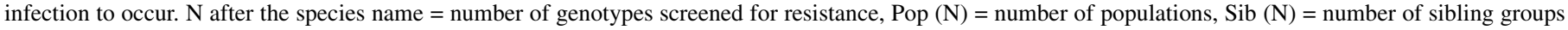
within each population, and New sib $(\mathrm{N})$ = number of sibling groups added into the experiment in 2013 . 
Resistance screening of material from growth chambers. In the summer of 2012, initial resistance screening of S. physalifolium, $S$. nigrum, and $S$. dulcamara was performed using 5-week-old plants from the growth chamber (Fig. 1). Complementary resistance screening of a second batch of plant material from growth chambers was also conducted in the summer of 2013 for two $S$. dulcamara populations to increase the sample size, allowing us to test for differences between populations and investigate variability within sibling groups (each sibling group contained half-sib and/or full-sib genotypes as they originated from individual plant of a given population). For the second batch, two populations were selected, Geneticum and Lomma2 (Fig. 1), based on differences in their resistance variability patterns in the 2012 screening (described in Results section). These natural populations also differed in growth habitat; ruderal Geneticum plants grew on a sunny site in the city of Lund $\left(55^{\circ} 71^{\prime} \mathrm{N}, 13^{\circ} 18^{\prime} \mathrm{E}\right)$, while Lomma 2 plants grew in half-shade on partly forested land along a road close to the sea outside the town of Lomma $\left(55^{\circ} 67^{\prime} \mathrm{N}, 13^{\circ} 06^{\prime} \mathrm{E}\right)$.

Resistance screening of material from the experimental garden and natural infections. One week after the resistance screening of the plant material from growth chambers in 2012 and 2013, all genotypes were acclimatized in a greenhouse and transferred into the experimental garden. Resistance screening in S. nigrum and $S$. dulcamara was performed after 4 weeks of growth in the experimental garden (Fig. 1). However, we could not screen $S$. physalifolium in 2012 because no plants survived the transplant to the experimental garden. At the end of the summer 2012, all the annual $S$. nigrum were removed from the experimental garden; but the $99 \mathrm{~S}$. dulcamara genotypes were cut at $10 \mathrm{~cm}$ above ground and left in the experimental garden for resistance screening in 2013 to 2014 (Fig. 1). Together with the 65 genotypes from the Geneticum and Lomma2 populations that were added to the experiment in 2013, a total of 164 S. dulcamara genotypes representing 35 sibling groups of 12 populations were tested for resistance in the summer of 2013 and 2014 (Fig. 1). During these experiments, all plant genotypes were inspected for any symptoms of natural infection of $P$. infestans.

$S$. physalifolium genotypes were found to be susceptible to $P$. infestans in the detached leaf assay using material from the growth chamber screening. Unfortunately, we could not subsequently evaluate their field performance in 2012 due to the plants dying when they were transferred to the field. To compensate for this, 48 S. physalifolium plants from two genotypes (generated from self-pollinated berries) were planted in the experimental garden in 2013 and subjected to natural infection by the pathogen. The proportion of infected leaves was recorded at the end of August. To be able to investigate the cost of infection on final plant size, the fresh and dry weight of the above-ground parts were measured at the end of the growing season.

Qualitative and quantitative measures of resistance in detached leaf assays. Both qualitative and quantitative measures were collected from the detached leaf assays at 7 days after inoculation (dai). To identify resistance phenotypes (qualitative disease scores), genotypes were classified into different resistance groups $\left(\mathrm{R}, \mathrm{R}^{\mathrm{N}}\right.$, and S) (Lebecka 2008) and into a fourth resistance phenotype, $S^{L}$, that was characterized as having lesions larger than the point of inoculation but with no visible sporulation of the pathogen. For each wild species, a genotype was identified as belonging to a resistance

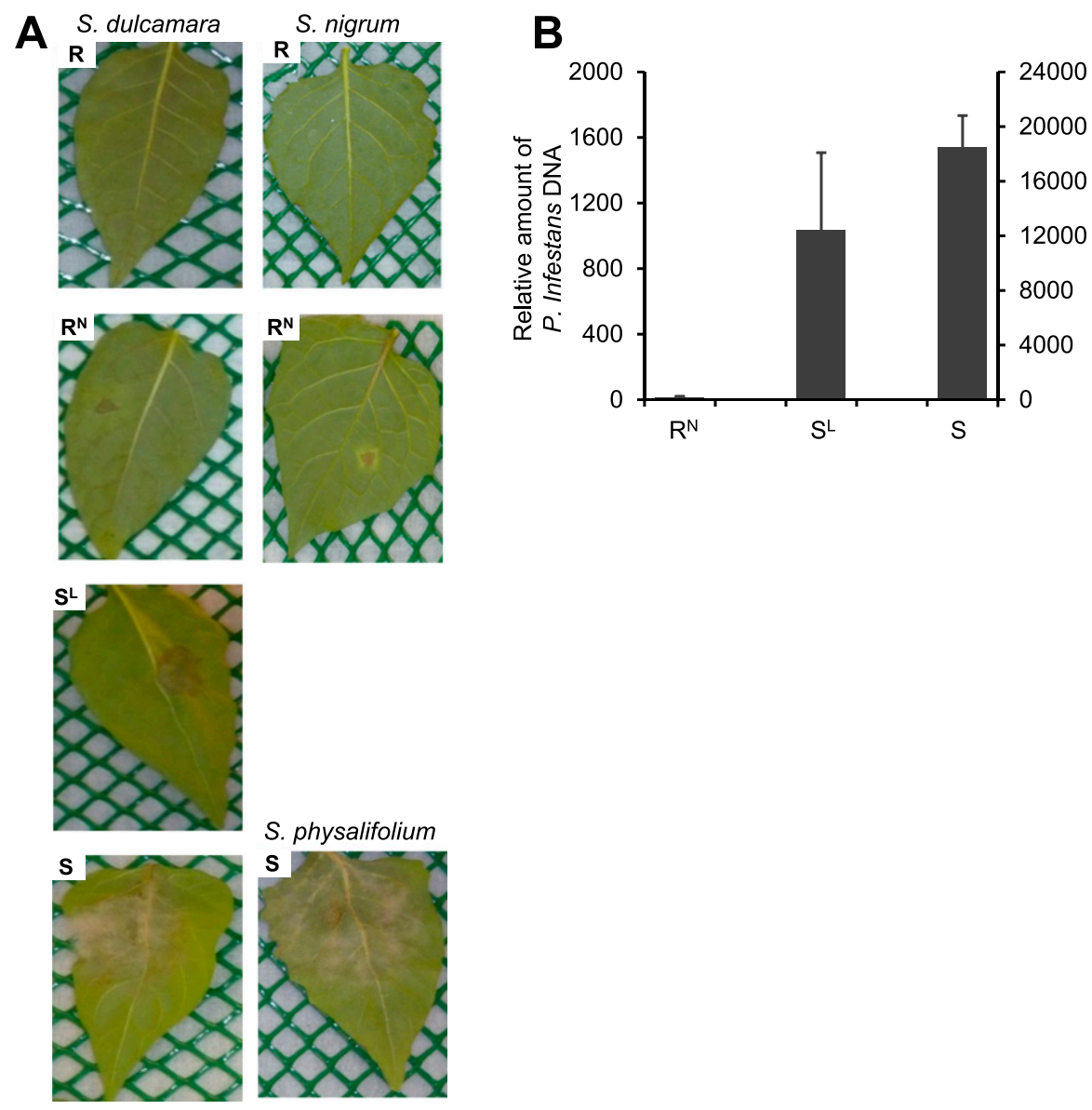

Fig. 2. Qualitative Phytophthora infestans resistance in leaves of Solanum dulcamara, S. nigrum, and S. physalifolium and relative abundance of P. infestans. A, Resistance phenotypes were identified following detached leaf assays: leaves without any symptoms (R); leaves with a small necrotic area $\left(\mathrm{R}^{\mathrm{N}}\right)$; leaves with a necrotic area larger than the point of inoculation $\left(S^{L}\right)$; and leaves with a sporulating pathogen $(S)$. Resistance phenotypes were determined at 7 days after inoculation. B, Abundance of $P$. infestans biomass, relative to the potato house-keeping gene EFla, in $S$. dulcamara genotypes displaying different resistance phenotypes measured by qPCR. Left axis indicates abundance of $P$. infestans in phenotype $\mathrm{R}^{\mathrm{N}}$ and $\mathrm{S}^{\mathrm{L}}$, whereas right axis indicates the abundance in $\mathrm{S}$ phenotype. 
group if at least three of five detached inoculated leaves in each experiment showed a particular resistance phenotype. For quantitative data, the short and long axes of the lesion on each detached leaf were measured and area of the lesion was calculated using the formula for an elliptical shape.

Quantification of $\mathrm{P}$. infestans biomass using qPCR. A quantitative PCR (qPCR) was performed in order to measure the $P$. infestans biomass on $S$. dulcamara genotypes displaying different macroscopic resistance phenotypes $\left(\mathrm{R}^{\mathrm{N}}, \mathrm{S}^{\mathrm{L}}\right.$, and $\left.\mathrm{S}\right)$. Five detached leaves of chamber-grown $S$. dulcamara genotypes were inoculated using the technique described above. At 7 dai, the resistance phenotype in each detached leaf was noted and leaf discs $(13 \mathrm{~mm})$ surrounding the point of inoculation were excised using a core borer. Leaf discs together with three glass beads were placed in preweighed 2-ml Eppendorf tube and frozen immediately in liquid nitrogen. Samples were pulverized with the Retsch MM 400 Mixer Mill (Retsch GmbH, Haan), with a frequency of $30 \mathrm{~Hz}\left(1,800 \mathrm{~min}^{-1}\right)$ for $15 \mathrm{~s}$. The machine tube holders were frozen in liquid nitrogen to ensure that the samples stayed frozen during homogenization. gDNA was extracted using DNeasy Plant Mini Kit (Qiagen), DNA was eluted with $20 \mu \mathrm{l}$ of MQ water, and DNA concentration was quantified with the Nanodrop ND-1000 spectrophotometer. For the quantification of
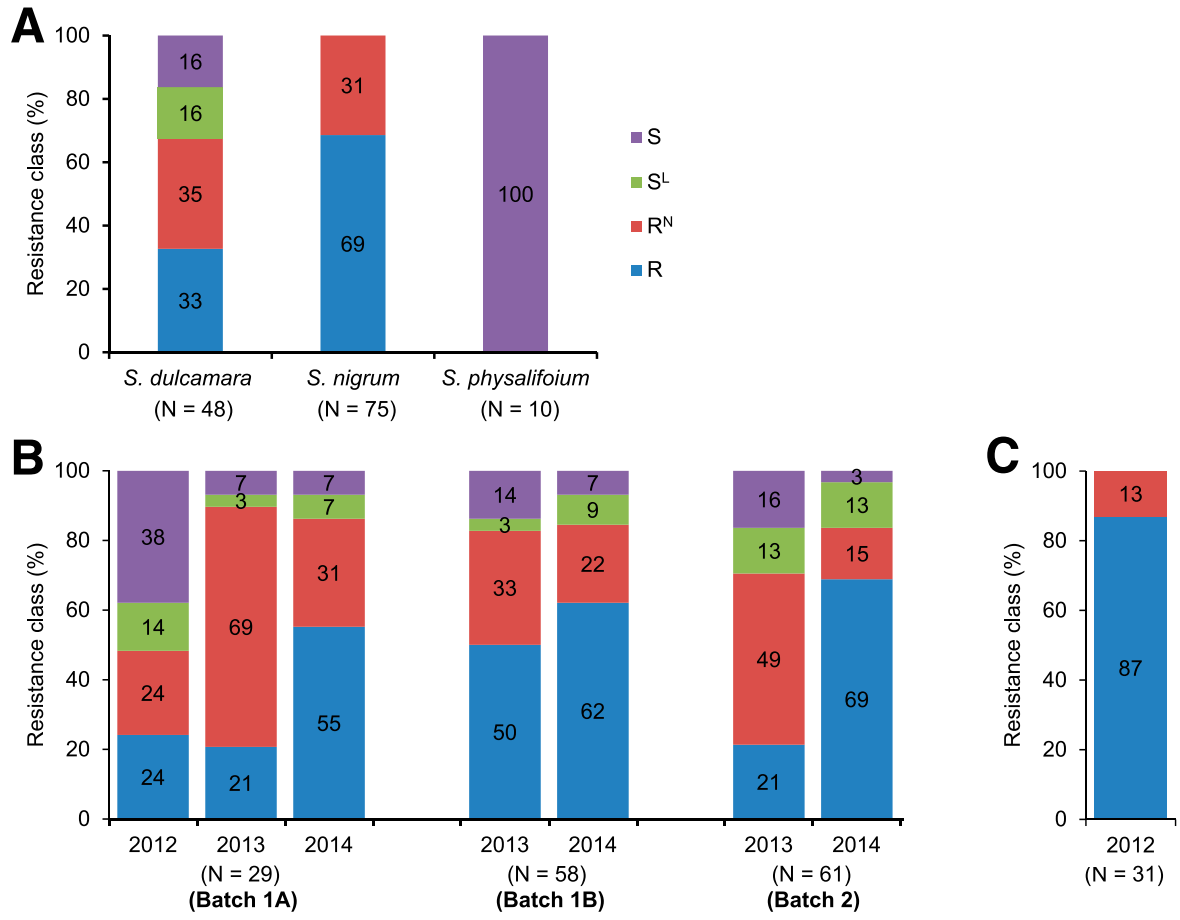

Fig. 3. Proportion of the four resistance classes of qualitative Phytophthora infestans resistance in Solanum dulcamara, S. physalifolium, and S. nigrum. A, Genotypes grown in a growth chamber in 2012 and screened for resistance using detached leaf assays. B, S. dulcamara genotypes screened for resistance in the experimental garden. Batch 1A was screened in 2012, 2013, and 2014. Batch 1B was transferred to the experimental garden in 2012 as in batch 1A, but was screened only in 2013 and 2014. Batch 2 was transferred into the experimental garden in 2013 to expand the Lomma2 and Geneticum populations and was screened in 2013 and 2014. C, S. nigrum genotypes screened for resistance in the experimental garden at Alnarp in 2012. P. infestans resistance phenotypes were determined at 7 days after inoculation.
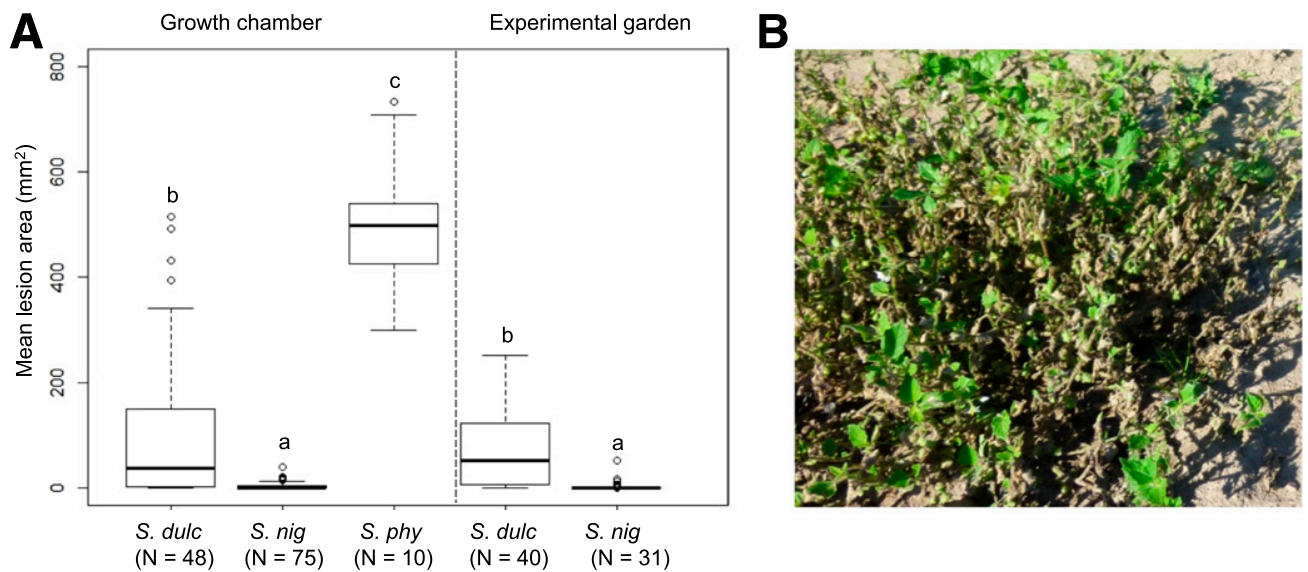

Fig. 4. Quantitative Phytophthora infestans resistance in Solanum dulcamara, S. nigrum, and S. physalifolium. A, Boxplots for mean lesion area following assays of detached leaves taken from genotypes grown in growth chambers and in the experimental garden in 2012, at 7 days after inoculation. Genotypes from the growth chamber were transferred to the experimental garden and rescreened for resistance after 4 weeks (Fig. 1). In the experimental garden, no screening was performed using $S$. physalifolium because these plants died. Separate tests were performed for the growth chamber and experimental garden experiments, and boxes with different lowercase letters are significantly different as determined using the Kruskal-Wallis rank sum test $(P<0.05)$. $\mathrm{N}=$ number of genotypes. B, $S$. physalifolium plants $(n=48)$ from two populations were grown in the experimental garden in 2013 and left to be infected by natural inoculum of $P$. infestans. 
$P$. infestans biomass, each sample was analyzed in triplicates using the primers PIO8-3-3F-mod (5'-CAATTCCCAACCTTCTCGGA-3') and PIO8-3-3-R (5'-GCCTTCCTGCCCTCAAGAAC-3') (Bengtsson et al. 2014a), and StEF1a-F (5'-TGAGGCAAACTGTTGCTGTC-3') and StEF1a-R (5'-TGGAAACACCAGCATCACAC- $\left.{ }^{\prime}\right)$ as a reference. The reaction mixture contained $10 \mu \mathrm{l}$ of SYBR Green, $0.4 \mu \mathrm{l}$ of diluted primers $(10 \mu \mathrm{M}), 2 \mu \mathrm{l}$ of DNA, and $7.2 \mu \mathrm{l}$ of MQ water. The qPCR conditions for amplification were 1 cycle of $5 \mathrm{~min}$ at $95^{\circ} \mathrm{C}$ followed by 40 cycles of $15 \mathrm{~s}$ at $95^{\circ} \mathrm{C}, 25 \mathrm{~s}$ at $60^{\circ} \mathrm{C}$, and $95^{\circ} \mathrm{C}$ for $10 \mathrm{~s}$. Biomass of $P$. infestans in the samples was calculated as described previously (Bengtsson et al. 2014a).

Collection of performance phenotype data in $\mathbf{S}$. dulcamara. To study the association between resistance and plant performance, we measured eight quantitative and two qualitative growth and reproductive parameters of all the $S$. dulcamara genotypes $(n=164)$ in the experimental garden 2013. On 25 July, the length of the longest branch of each plant ( $\mathrm{mm}$ ) and the number of branches per plant were recorded as indicators of plant size. Based on plant growth habit, each plant was classified as either upright or creeping, as well as measured its vertical height (distance from ground to top of the plant) $(\mathrm{mm})$, and its radius (average of short and longest axis of ground cover of the plant canopy) (mm). Genotypes were also classified as having glossy or nonglossy leaves as this could be related to mechanical resistance. To obtain information relating to the reproductive potential of the genotypes, on 15 August, five ripe berries per plant were collected and their seeds extracted. Dried seeds were counted and weighed to obtain an average weight per seed. On 16 September, at the end of the growing season, we cut the plants at ca. $10 \mathrm{~cm}$ above ground and immediately weighed them to obtain fresh weight data. These plants were then dried indoors at room temperature and dry weight (including berries), number of berries per plant, and berry weight were measured.

Statistical analysis. Kruskal-Wallis and pairwise comparisons, with the Tukey and Kramer (Nemenyi) test in the ' $R$ ' statistical package pairwise multiple comparisons of mean rank sums (PMCMR) (Pohlert 2015), was used for tests of whether the classified resistance phenotypes differed in lesion area and biomass of $P$. infestans, and whether the three Solanum species differed in lesion area. Spearman's rho rank correlations in the ' $R$ ' statistical package 'corrplot' (Wei 2013) was used to determine similarity in lesion area in S. dulcamara genotypes from the growth chamber and experimental garden, and between the percentage of natural infection in $S$. physalifolium and dry and fresh weight. We used nonparametric tests because the data were not normally distributed.

To unravel the percentage variance attributable to year, population and sibling group for lesion area in the experimental garden in the $12 \mathrm{~S}$. dulcamara populations, a random-effects model was fitted with the random factors year, population, and sibling group nested within population, using restricted maximum likelihood. This method provides quantitative estimates of relative importance of the random factors and it is robust to unbalanced data. The analysis was performed in SPSS version 24.0 (SPSS 2016). Differences in lesion area between the $12 \mathrm{~S}$. dulcamara populations or between the two expanded populations were tested using Kruskal-Wallis. Additionally, the 12 populations were classified into sunny $(n=5)$ and half-shade $(n=7)$, and tested whether light condition had an effect on lesion area. Levene's test for equality of variance was applied to test if the pattern of resistance variation within the two
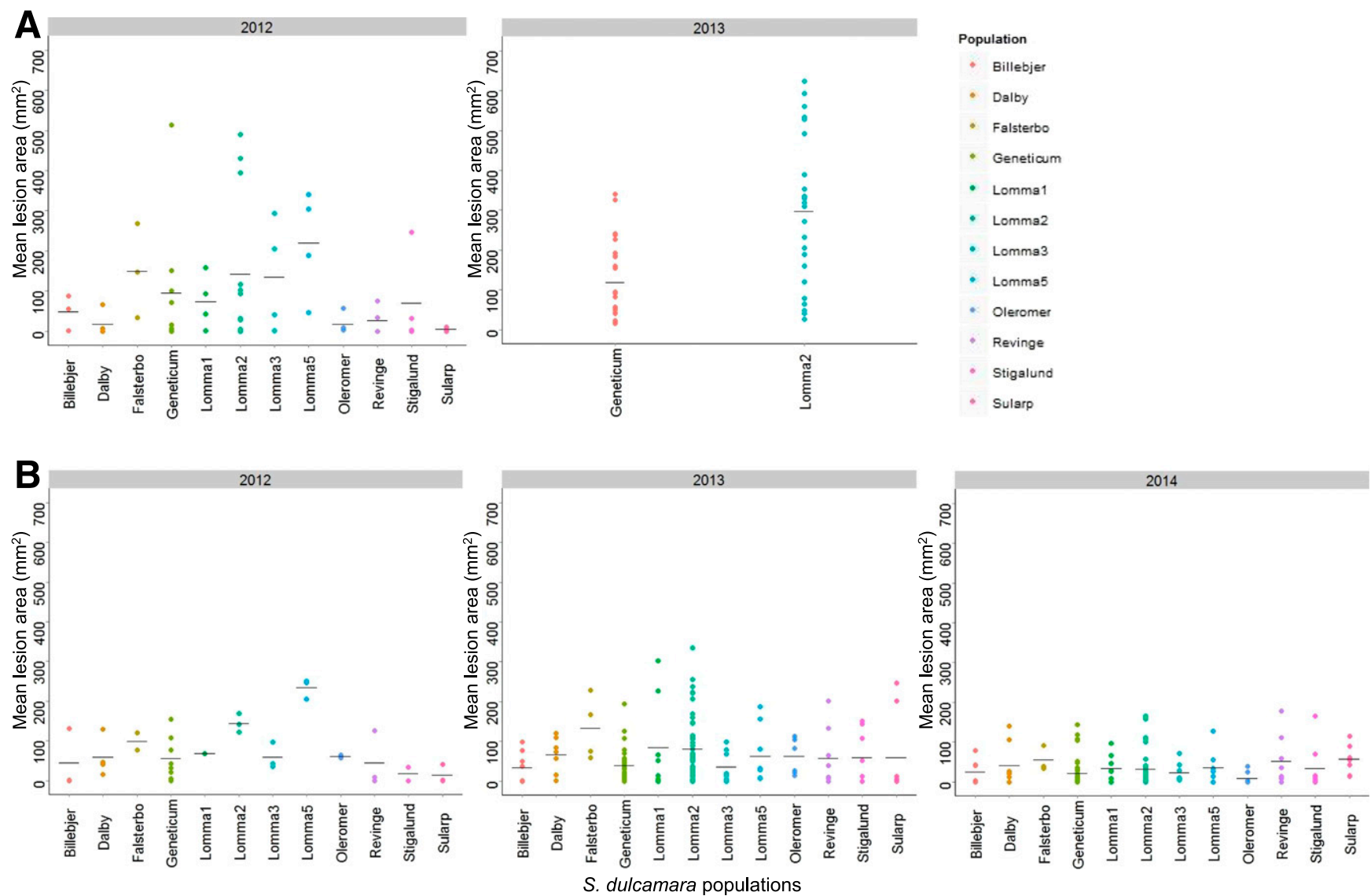

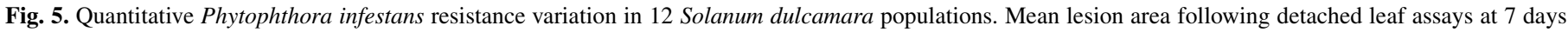

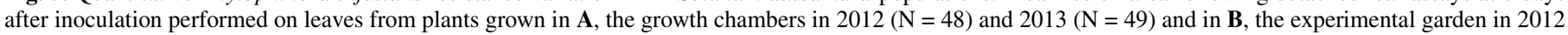

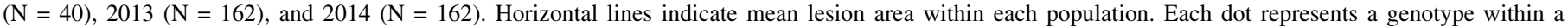
population, based on an average of five inoculated leaves. $\mathrm{N}=$ number of genotypes. 
expanded $S$. dulcamara populations was similar, i.e., homogeneity of variances.

Data on performance parameters and lesion area comparisons collected in 2013 were compared between S. dulcamara populations using multivariate analysis of variance (MANOVA) in ' $R$ '. In this test, the performance parameters and lesion area were dependent variables, whereas the population was the independent variable. We used Spearman's rho rank correlation to investigate relationships between the quantitative performance parameters, and between lesion area and performance parameters calculated as mean values for each sibling group. The Kruskal-Wallis test was used to test whether the quantitative performance traits (upright versus creeping and glossy versus nonglossy leaves) differed in lesion area.

\section{RESULTS}

Identification of four $P$. infestans resistance phenotypes in the three Solanum species. Based on the resistance reaction at 7 dai in the detached leaf assays in S. dulcamara, S. nigrum, and $S$. physalifolium (Fig. 1), a new resistance phenotype, $\mathrm{S}^{\mathrm{L}}$, was identified in addition to the three described earlier. This resulted in four phenotypes: $\mathrm{R}$, without any visible infection symptoms; $\mathrm{R}^{\mathrm{N}}$, necrosis equal to or smaller than the area of inoculation and with no sporulation; $\mathrm{S}^{\mathrm{L}}$, lesion size larger than the area of inoculation but without visible sporulation; and $\mathrm{S}$, sporulating large lesions (Fig. 2A).

All four resistance phenotypes were found in S. dulcamara, and $\mathrm{R}$ and $\mathrm{R}^{\mathrm{N}}$ in $S$. nigrum, while only $\mathrm{S}$ was identified in $S$. physalifolium (Fig. 2A). Comparing the quantitative measure of mean lesion area in the four resistance phenotypes in S. dulcamara, conducted in 2012 on plants from the growth chamber and experimental garden, showed that the mean lesion area differed significantly between the resistance phenotypes (Kruskal-Wallis $\chi^{2}=85.9$, df $=3, P<0.001$ ) (Supplementary Fig. S2). Moreover, the $\mathrm{S}$ phenotypes in $S$. physalifolium $(\mathrm{N}=10)$ and $S$. dulcamara $(\mathrm{N}=8)$ plants from the growth chamber in 2012 did not differ in average mean lesion area (Kruskal-Wallis rank sum test, $\chi^{2}=1.8, \mathrm{df}=1, P=0.2$ ).

In order to substantiate the new resistance classes of phenotypes, qPCR was carried out and showed that biomass of $P$. infestans was significantly higher in $S$. dulcamara genotypes with $\mathrm{S}$ phenotype (relative abundance 18,531) than in genotypes with $S^{L}$ (relative abundance 1,036) (Kruskal-Wallis $\chi^{2}=62.5476, \mathrm{df}=2, P<0.001$ ) (Fig. 2B). Similarly, $\mathrm{S}$ and $\mathrm{S}^{\mathrm{L}}$ were significantly higher than $\mathrm{R}^{\mathrm{N}}$ (relative abundance 16) (Kruskal-Wallis $\chi^{2}=62.5, \mathrm{df}=2, P<0.001$ (S); 62.5476, df = 2, $P=0.004\left(\mathrm{~S}^{\mathrm{L}}\right)$ ) (Fig. 2B).

Differences in $P$. infestans resistance among the three Solanum species. The resistance screening on the material from the growth chamber in 2012 showed that in S. dulcamara $(\mathrm{N}=48$ from 12 populations), where all resistance phenotypes were observed, the $\mathrm{R}$ and $\mathrm{R}^{\mathrm{N}}$ phenotypes were found at relatively higher frequencies than the $\mathrm{S}^{\mathrm{L}}$ and $\mathrm{S}$ phenotypes $\left(33 \% \mathrm{R}, 35 \% \mathrm{R}^{\mathrm{N}}, 16 \% \mathrm{~S}^{\mathrm{L}}\right.$, and $16 \% \mathrm{~S}$ ) (Fig. 3A). In S. nigrum ( $\mathrm{N}=75$ from 20 populations), two thirds were of the $\mathrm{R}(69 \%)$ and one third of the $\mathrm{R}^{\mathrm{N}}(31 \%)$ resistance phenotypes. In contrast, all investigated $S$. physalifolium genotypes $(\mathrm{N}=10$ from three populations) were characterized as susceptible (S) (Fig. 3A). Comparing the quantitative measure for the three species confirmed the qualitative results, as mean lesion size in S. physalifolium was significantly larger than in S. dulcamara $(P<$ $0.01)$ and $S$. nigrum $(P<0.01)$ (Kruskal-Wallis rank sum test, $\chi^{2}=$ 57.0154, df =2) (Fig. 4A). Moreover, the mean lesion size in $S$. nigrum was significantly smaller than in $S$. dulcamara (KruskalWallis rank sum test, $\chi^{2}=57$, df $=2, P<0.01$ ) (Fig. 4A).

One week after the initial resistance screen in 2012, chambergrown plants were transferred to the experimental garden and $S$. nigrum and $S$. dulcamara genotypes grown there were rescreened for P. infestans resistance (Fig. 1). We did not detect any symptoms of natural infection in S. nigrum and S. dulcamara plants. Of the 29 $S$. dulcamara genotypes tested in detached leaf assays from the experimental garden in 2012, 24\% showed the R, 24\% the $\mathrm{R}^{\mathrm{N}}, 14 \%$ the $\mathrm{S}^{\mathrm{L}}$, and $38 \%$ the $\mathrm{S}$ resistance phenotypes (Fig. 3B, batch 1A). In the experimental garden, $87 \%$ of the $S$. nigrum genotypes $(\mathrm{N}=31)$ grown in 2012 displayed the $\mathrm{R}$ phenotype while the remaining $13 \%$ displayed the $\mathrm{R}^{\mathrm{N}}$ phenotype (Fig. $3 \mathrm{C}$ ). Similar to the growth chamber results, the mean lesion size in $S$. nigrum was significantly smaller than in $S$. dulcamara in the experimental garden $(P<0.01)$ (Kruskal-Wallis rank sum test, $\chi^{2}=34.3, \mathrm{df}=1, P<0.01$ ) (Fig. 4A). Moreover, there was a moderate positive correlation between the lesion area of chamber- and garden-grown $S$. dulcamara genotypes in 2012 (Spearman $r^{2}=0.59, \mathrm{~N}=35, P<0.05$, Supplementary

TABLE 1. Resistance to Phytophthora infestans and performance trait measurements of Solanum dulcamara populations ${ }^{\mathrm{a}}$

\begin{tabular}{|c|c|c|c|c|c|c|c|c|c|}
\hline \multirow[b]{2}{*}{ Population } & \multirow[b]{2}{*}{ Habitat } & \multirow[b]{2}{*}{ Light conditions } & \multirow{2}{*}{$\begin{array}{l}\text { Number of individual } \\
\text { genotypes (from number } \\
\text { of sibling groups) }\end{array}$} & \multicolumn{4}{|c|}{$\begin{array}{c}\text { Number of resistance } \\
\text { phenotypes }\end{array}$} & \multirow[b]{2}{*}{ Plants upright } & \multirow{2}{*}{$\begin{array}{l}\text { Plants with } \\
\text { glossy leaf }\end{array}$} \\
\hline & & & & $\mathrm{R}$ & $\mathrm{Rn}$ & $\mathrm{Sn}$ & Ss & & \\
\hline Billebjer & Damp forest around pond & Half-shade & $8(2)$ & 5 & 2 & & & $13 \%$ & $25 \%$ \\
\hline Dalby 1 & In forest & Half-shade & $8(2)$ & 3 & 3 & 1 & 1 & $38 \%$ & $38 \%$ \\
\hline Falsterbo & Dunes, next to wooded area & Half-shade & $4(1)$ & & & 2 & 2 & $25 \%$ & $75 \%$ \\
\hline Lomma 1 & Forest marsh & Half-shade & $8(2)$ & 4 & 2 & & 1 & $25 \%$ & $50 \%$ \\
\hline Lomma 2 & Forest along road & Half-shade & $42(8)$ & 11 & 15 & 4 & 9 & $60 \%$ & $41 \%$ \\
\hline Oleromers & Hedge along road, urban area & Half-shade & $8(2)$ & 1 & 5 & 1 & & $63 \%$ & $50 \%$ \\
\hline Sularp & Ditch, along bike track & Half-shade & $8(2)$ & 5 & & & 3 & $88 \%$ & $50 \%$ \\
\hline Geneticum & Ruderal land, urban area & Sunny & $44(8)$ & 9 & 30 & 3 & 2 & $73 \%$ & $66 \%$ \\
\hline Lomma 3 & Sandy beach & Sunny & $8(2)$ & 3 & 3 & 1 & & $13 \%$ & $88 \%$ \\
\hline Lomma 5 & Ruderal land, along road & Sunny & $8(2)$ & & 5 & 2 & & $75 \%$ & $88 \%$ \\
\hline Revinge & Marsh & Sunny & $8(2)$ & 3 & 3 & & 1 & $88 \%$ & $75 \%$ \\
\hline $\begin{array}{l}\text { Stigalund } \\
F \text { value }\end{array}$ & Sandy pasture along stream & Sunny & $8(2)$ & 4 & 1 & 1 & 2 & $100 \%$ & $88 \%$ \\
\hline
\end{tabular}

$P$ value

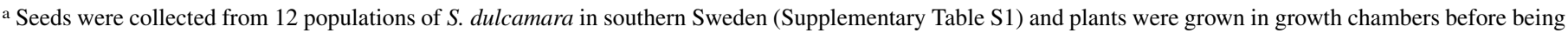
transferred to the experimental garden in 2013. Plants were screened for resistance to P. infestans and lesion size was measured at 7 days after inoculation. According to their resistance reaction, $S$. dulcamara genotypes were classified into different resistance phenotypes. Habitat describes the natural environment at the collection sites (populations), and these sites were further classified as half-shade or sunny based on the light condition. Based on the growth habit and glossiness of their leaves, genotypes of $S$. dulcamara were grouped as growing-upright/creeping, and glossy/not glossy. Moreover, data were collected on phenotypic performance parameters (Figure 6 provides a description of the measured traits). Comparisons among the populations for the performance traits and lesion area were performed using multivariate analysis of variance. Values for performance traits (mean $\pm \mathrm{SE}$ ).
} 
Fig. S3), indicating that the screening results were reproducible under both growing conditions.

Resistance screening and observation of natural infection in S. physalifolium were not conducted in 2012 because no plants of this species were established successfully in the experimental garden. Therefore, to evaluate the resistance of field-grown S. physalifolium, 48 plants from two genotypes, the Lars (L) and Lillgårda (I) populations, were grown in the experimental garden in 2013 and were subjected to natural P. infestans infection (Fig. 4B). We observed that $S$. physalifolium plants of both genotypes were highly infected, with average percentage of infection in $\mathrm{L}=69 \%$ and $\mathrm{I}=53 \%$ ). Plants shed blighted leaves and regrew new leaves (Fig. 4B). Despite the regrowth, the percentage of infected leaves per plant was negatively correlated with fresh weight (Spearman $r^{2}=-0.53$, $\mathrm{N}=48, P<0.001$ ) and dry weight of the plant (Spearman's $r^{2}=-0.50$, $\mathrm{N}=48, P<0.05$ ), measured at the end of the growing season.

Variation in $P$. infestans resistance in $S$. dulcamara populations and sibling groups. Because of the large resistance variation found among $S$. dulcamara genotypes, the resistance of the 12 populations of this species across three years in the experimental garden was examined. To further investigate resistance variation between populations as well as between sibling groups within populations, two of the investigated populations, Geneticum and Lomma2, were also expanded by adding new genotypes (Fig. 1). Lomma2 showed higher variability in lesion size than Geneticum in growth-chamber grown plants in 2012 (Levene's test, $\mathrm{F}_{(1,24)}=4.8, P<0.03$ ) (Fig. 5A).

All four resistance phenotypes were present in each year, in the 164 genotypes of the $12 \mathrm{~S}$. dulcamara populations screened for resistance across 2012 to 2014 in the experimental garden, (Fig. 3B). Lesion area also showed wide variation among genotypes from the same population in 2012 and 2013 using plants from growth chambers, and in 2012 to 2014 using plants from the experimental garden (Fig. 5).

Based on data from the experimental garden in 2013, mean lesion area did not differ among the 12 investigated populations (KruskalWallis $\chi^{2}=15.7$, $\mathrm{df}=11, P=1$ ) or between sunny and half-shade populations $(0.01, \mathrm{df}=1, P=0.9)$ (Table 1$)$. Year, population and sibling group within population described $13,2.9$, and $4.4 \%$, respectively, of the variation in lesion size for the field data across the 3 years. Thus, most variation was found within sibling groups (79.7\%).
To better understand the differences in resistance between S. dulcamara populations and within sibling groups, lesion size of the Geneticum $(\mathrm{N}=44)$ and Lomma2 $(\mathrm{N}=43)$ populations was compared using a larger sample size in 2013 and 2014. In chambergrown plants, resistance screening in 2013 indicated that there was a difference in the mean lesion area between Lomma2 $\left(296 \mathrm{~mm}^{2}, \mathrm{~N}=\right.$ 24) and Geneticum (118 $\left.\mathrm{mm}^{2}, \mathrm{~N}=25\right)$ (Kruskal-Wallis $\chi^{2}=12.0$, $\mathrm{df}=1, P<0.01)($ Fig. 5A). Moreover, the within-population resistance variation was higher in Lomma2 $\left(\sigma^{2}=38\right)$ compared with Geneticum $\left(\sigma^{2}=19.8\right)$ (Levene's test, $\mathrm{F}_{(1,47)}=7.9, P<0.01$ ) (Fig. 5A), in line with the result from 2012. In the experimental garden, mean lesion area differed between populations in 2013 (Lomma2: $81 \mathrm{~mm}^{2}, \mathrm{~N}=43$; Geneticum $39 \mathrm{~mm}^{2}, \mathrm{~N}=44$; KruskalWallis $\chi^{2}=4.3, \mathrm{df}=1, P=0.03$ ) but not in 2014 (Lomma2: $31 \mathrm{~mm}^{2}$, $\mathrm{N}=43$; Geneticum $21.5 \mathrm{~mm}^{2}, \mathrm{~N}=42$; Kruskal-Wallis $\chi^{2}=19.8, \mathrm{df}=$ $1, P=0.9$ ) (Fig. 5B). Similarly, the within-population variance was higher in Lomma2 $\left(\sigma^{2}=12.6\right)$ than in Geneticum $\left(\sigma^{2}=5.6\right)$ (Levene's test, $\left.\mathrm{F}_{(1,85)}=13.4, P<0.001\right)$ in 2013, while no significant difference in variance was seen in 2014 (Lomma2: $\sigma^{2}=7$, Geneticum: $\sigma^{2}=5.3$; Levene's test, $\left.\mathrm{F}_{(1,83)}=1.3, P=0.26\right)$ (Fig. 5B).

In line with the overall analysis of the variance components of lesion size for the field data, the variability was substantial within sibling groups for resistance phenotypes in Geneticum and Lomma2 populations (Table 2). Different resistance phenotypes $\left(\mathrm{R}, \mathrm{R}^{\mathrm{N}}, \mathrm{S}^{\mathrm{L}}\right.$, and in some instances $\mathrm{S}$ ) were found within the same $S$. dulcamara sibling groups (Table 2). The lesion size among the sibling genotypes varied from no lesion $\left(0 \mathrm{~mm}^{2}\right)$ to a large lesion area $\left(250 \mathrm{~mm}^{2}\right)$ as shown in the Lomma2_10 sibling group in 2013 (Supplementary Fig. S4).

$P$. infestans resistance and performance parameters in S. dulcamara. To investigate variation between populations in growth and reproductive performance as well as to estimate cost of resistance, data for eight quantitative and two qualitative performance parameters were collected 2013 in the experimental garden for each $S$. dulcamara genotype (Table 1). Significant differences among the $S$. dulcamara populations were noted in all of the traits (MANOVA, $P \leq 0$. 05), except for lesion area $(P=0.1)$, longest branch $(P=0.06)$, and berry weight $(P=0.08)$ (Table 1$)$. Strong correlations were found between performance traits indicating plant size (the midseason measures longest branch and number of branches), and fresh and dry weight at the end of the growing season

TABLE 1. (Continued from previous page)

\begin{tabular}{|c|c|c|c|c|c|c|c|c|c|}
\hline $\begin{array}{l}\text { Lesion area } \\
\qquad\left(\mathrm{mm}^{2}\right)\end{array}$ & $\begin{array}{c}\text { Longest } \\
\text { branch }(\mathrm{mm})\end{array}$ & $\begin{array}{c}\text { Vertical } \\
\text { height }(\mathrm{mm})\end{array}$ & $\begin{array}{l}\text { Radius } \\
(\mathrm{mm})\end{array}$ & $\begin{array}{c}\text { Number of } \\
\text { branches }\end{array}$ & $\begin{array}{l}\text { Fresh weight } \\
\text { (Palmgren } \\
\text { et al. 2015) }\end{array}$ & $\begin{array}{l}\text { Dry weight } \\
\text { (Palmgren } \\
\text { et al. 2015) }\end{array}$ & $\begin{array}{l}\text { Berry weight } \\
\text { (Palmgren } \\
\text { et al. 2015) }\end{array}$ & $\begin{array}{c}\text { Number of } \\
\text { berries } \\
\text { per plant }\end{array}$ & $\begin{array}{l}\text { Seed weight } \\
\text { (Palmgren } \\
\text { et al. 2015) }\end{array}$ \\
\hline $33 \pm 14$ & $745 \pm 33$ & $406 \pm 27$ & $582 \pm 29$ & $8 \pm 0.8$ & $1,103 \pm 292$ & $332 \pm 55$ & $62 \pm 3$ & $883 \pm 228$ & $1.5 \pm 0.1$ \\
\hline $66 \pm 17$ & $690 \pm 38$ & $408 \pm 36$ & $514 \pm 34$ & $8.5 \pm 1.0$ & $762 \pm 127$ & $368 \pm 63$ & $61 \pm 12$ & $677 \pm 199$ & $1.6 \pm 0.1$ \\
\hline $132 \pm 40$ & $792 \pm 92$ & $412 \pm 55$ & $508 \pm 76$ & $5.7 \pm 1.3$ & $1,599 \pm 353$ & $599 \pm 120$ & $64 \pm 13$ & $672 \pm 134$ & $1.9 \pm 0.2$ \\
\hline $84 \pm 41$ & $828 \pm 49$ & $472 \pm 40$ & $644 \pm 42$ & $8.8 \pm 0.7$ & $1,704 \pm 275$ & $508 \pm 123$ & $82 \pm 4$ & $1,237 \pm 202$ & $1.9 \pm 0.1$ \\
\hline $81 \pm 13$ & $678 \pm 63$ & $370 \pm 23$ & $355 \pm 42$ & $6.0 \pm 1.1$ & $513 \pm 282$ & $219 \pm 108$ & $65 \pm 10$ & $247 \pm 170$ & $1.9 \pm 0.1$ \\
\hline $62 \pm 16$ & $822 \pm 37$ & $580 \pm 23$ & $603 \pm 35$ & $10.6 \pm 1$ & $2,237 \pm 376$ & $900 \pm 154$ & $78 \pm 4$ & $1,425 \pm 265$ & $1.8 \pm 0.0$ \\
\hline $59 \pm 36$ & $823 \pm 45$ & $643 \pm 43$ & $613 \pm 50$ & $8.7 \pm 1.3$ & $761 \pm 107$ & $316 \pm 38$ & $55 \pm 8$ & $413 \pm 77$ & $1.9 \pm 0.0$ \\
\hline $39 \pm 6$ & $673 \pm 30$ & $440 \pm 36$ & $357 \pm 41$ & $6.5 \pm 0.9$ & $673 \pm 145$ & $273 \pm 31$ & $61 \pm 5$ & $270 \pm 121$ & $1.7 \pm 0.1$ \\
\hline $36 \pm 14$ & $752 \pm 42$ & $415 \pm 35$ & $575 \pm 32$ & $10.7 \pm 0.9$ & $2,073 \pm 227$ & $604 \pm 69$ & $82 \pm 5$ & $1,421 \pm 206$ & $2.0 \pm 0.0$ \\
\hline $64 \pm 25$ & $778 \pm 73$ & $482 \pm 37$ & $535 \pm 55$ & $9.3 \pm 1.3$ & $1,919 \pm 462$ & $699 \pm 178$ & $193 \pm 106$ & $1,254 \pm 266$ & $2.1 \pm 0.0$ \\
\hline $57 \pm 26$ & $772 \pm 64$ & $582 \pm 38$ & $456 \pm 49$ & $9.3 \pm 1.3$ & $468 \pm 88$ & $199 \pm 27$ & $78 \pm 9$ & $258 \pm 54$ & $1.7 \pm 0.1$ \\
\hline $59 \pm 23$ & $648 \pm 39$ & $560 \pm 30$ & $395 \pm 45$ & $9.5 \pm 1.5$ & $686 \pm 124$ & $253 \pm 29$ & $54 \pm 8$ & $617 \pm 120$ & $1.3 \pm 0.0$ \\
\hline 1.6 & 1.8 & 7.5 & 9.6 & 3.5 & 8.2 & 7.4 & 1.9 & 8.3 & 2.9 \\
\hline 0.1 & 0.06 & $<0.001$ & $<0.001$ & $<0.001$ & $<0.001$ & $<0.001$ & 0.08 & $<0.001$ & $<0.01$ \\
\hline
\end{tabular}


(Fig. 6). These traits were also correlated with the number of berries per plant, but not with the other reproductive traits berry and seed weight. Regarding the growth habitat upright or creeping, estimated as two quantitative measures, genotypes with larger radius of canopy cover were generally larger and produced more berries, while a high vertical height had little influence on other performance traits (Fig. 6).

For the eight quantitative performance parameters, only number of branches per plant was significantly correlated with the lesion area (Fig. 6). The correlation was negative, meaning that more resistant genotypes with smaller lesions produced more branches. Moreover, no significant differences in lesion area were found between the qualitative measures glossy and nonglossy (KruskalWallis rank sum test, $\chi^{2}=0.4, \mathrm{df}=1, P=0.5$ ) or between upright and creeping plant type $(0.5$, df $=1, P=0.5)$ (Table 1$)$.

\section{DISCUSSION}

Investigating the resistance variation to $P$. infestans of wild Solanum species from several continents, potentially adapted to different climates and pathogen populations, can help understand the possible epidemiological role of these species and their use in potato breeding. Therefore, we studied the $P$. infestans resistance of all naturally occurring wild Solanum species (S. physalifolium, $S$. nigrum, and $S$. dulcamara) in Sweden; these Solanum species differed widely in their resistance to $P$. infestans. In these wild Solanum species, four resistance phenotypes were identified in the detached leaf assay, which indicate different resistance reaction against $P$. infestans, and help determine the potential importance of these species for epidemiology.

$S$. physalifolium is a susceptible host of $P$. infestans. All $10 \mathrm{~S}$. physalifolium genotypes investigated in this study were susceptible to $P$. infestans. Previously, it has been shown that $S$. physalifolium originating from Sweden is a host to $P$. infestans (Andersson et al. 2003; Gronberg et al. 2012; Lankinen et al. 2016). However, three genotypes were screened for resistance by Lankinen et al. (2016), whereas Andersson et al. (2003) and Gronberg et al. (2012) described Phytophthora from only a single plant population of $S$. physalifolium. It was noted that in 2013, naturally occurring

TABLE 2. Resistance phenotypes in sibling plants of Solanum dulcamara ${ }^{\text {a }}$

\begin{tabular}{llcccc}
\hline & & \multicolumn{4}{c}{$\begin{array}{c}\text { Number of plants with resistance } \\
\text { phenotype }\end{array}$} \\
\cline { 3 - 6 } Population & Sibling group & $\mathrm{R}$ & $\mathrm{R}^{\mathrm{N}}$ & $\mathrm{S}^{\mathrm{L}}$ & $\mathrm{S}$ \\
\hline Geneticum & Gen_11 & 1 & 4 & 1 & \\
& Gen_13 & & 2 & 1 & \\
& Gen_15 & 1 & 3 & & \\
& Gen_17 & & 3 & & \\
& Gen_20 & 1 & 1 & 1 & 1 \\
& Gen_21 & & 2 & & \\
& Gen_3 & & 2 & & \\
& Gen_4 & 2 & 2 & & \\
& TOTAL & $18 \%$ & $68 \%$ & $11 \%$ & $4 \%$ \\
& Lom2_10 & 2 & 2 & 1 & 1 \\
& Lom2_11 & 3 & 1 & 2 & \\
& Lom2_15 & 1 & & & 3 \\
& Lom2_19 & & 3 & & 1 \\
& Lom2_2 & 3 & 1 & 1 & 1 \\
& Lom2_3 & & & & 2 \\
& Lom2_4 & 1 & 3 & & 1 \\
& Lom2_8 & & 1 & & \\
& TOTAL & $29 \%$ & $32 \%$ & $12 \%$ & $26 \%$
\end{tabular}

a $S$. dulcamara plants were generated from seeds obtained in Geneticum and Lomma2 populations in southern Sweden. Plants were grown at the experimental garden in 2013 and screened for resistance against Phytophthora infestans. The resistance phenotype of each genotype was determined 7 days after inoculation, and numbers of genotypes within each population and sibling group are indicated under the resistance phenotype columns. A sibling group represents a group of genotypes grown from seeds obtained from the same mother plant.
$P$. infestans infected all $S$. physalifolium plants grown adjacent to the S. dulcamara plot at the Alnarp experimental garden. Similarly, Andersson et al. (2003) and Gronberg et al. (2012) were able to isolate $P$. infestans strains from naturally infected $S$. physalifolium plants grown in agricultural fields in southern Sweden. After years of scoring of Phytophthora symptoms in potato fields, we have not been able to find any variation in susceptibility within or between populations of $S$. physalifolium occurring in these fields.

In addition to confirming the susceptibility of $S$. physalifolium to $P$. infestans in Sweden, this study showed that naturally infected $S$. physalifolium plants could shed blighted leaves and regrow new leaves. Pathogen-induced defoliation of leaves has been described in other systems, for example in wild white clover (Trifolium repens) infected by rust (Uromyces sp.) (Nelson and Campbell 1993) and cotton infected by Verticillium dahliae (Zhang et al. 2012). The pathogen also infected plants of a susceptible potato genotype, grown in the same field as $S$. physalifolium, which did not show any premature leaf abscission. We have not observed premature leaf abscission in our potato field trials over the years. Despite the growth of new leaves, there was a negative correlation between the percentage of infection and fresh weight and dry weight of $S$. physalifolium plants suggesting that the pathogen attack was costly to the plants. The drop of leaves in S. physalifolium might be a mechanism to reduce the $P$. infestans pressure. Conversely, the fallen blighted leaves of $S$. physalifolium might facilitate build-up of soil inoculum. In southern Sweden, the soilborne oospore inoculum from infections in the previous year can initiate a late blight disease (Widmark et al. 2007).

Thus, given its presence in agricultural fields in southern Sweden, $S$. physalifolium can play an important role in the late blight epidemiology. Similar to the eradication program of $S$. dulcamara that was used for reducing the prevalence of $R$. solanacearum in the 1970s (Persson 1998), S. physalifolium could be considered as a potential target for an eradication program in order to limit $P$. infestans spread in southern Sweden.

S. nigrum is resistant to $P$. infestans. In this study, 75 Swedish S. nigrum genotypes, collected from 20 populations in southern Sweden; were tested and showed either a lesion that was restricted to the point of inoculation or no macroscopic symptoms of infection ( $\mathrm{R}$ and $\mathrm{R}^{\mathrm{N}}$ resistance phenotypes). There was no symptom of natural infection detected in S. nigrum genotypes grown in the Alnarp experimental garden in 2012 or in the potato fields that we have visited in the last 5 years. None of the pathogen isolates from southern Sweden (Andersson et al. 2003) and Poland (Lebecka 2008) were able to infect $S$. nigrum. Contradictory to this, susceptible $S$. nigrum genotypes from France, the United Kingdom, the Netherlands, Germany, and Poland were identified in a resistance screening using $P$. infestans isolates from Poland (Lebecka 2008) and natural infection in the Netherlands (Flier et al. 2003).

Flier et al. (2003) and Lebecka (2008) suggested that the resistance phenotype $\mathrm{R}^{\mathrm{N}}$ against $P$. infestans in $S$. nigrum might be conferred by $R$-genes. Consistent with this, $S$. nigrum has been suggested to contain $R l$ gene homologs (Gyetvai 2010). Moreover, monogenic dominant inheritance of $P$. infestans resistance has been suggested following analysis of the population derived from crossing a susceptible $S$. nigrum from Poland and a resistant $S$. nigrum from Germany (Lebecka 2009). Also, Rl-gene like sequences were identified in a transcriptomic analysis of $S$. nigrum infected with $P$. infestans (Frades et al. 2015). Overall, the results indicate a possibility of using $S$. nigrum as a source of resistance in potato breeding.

$S$. nigrum plays an important role in the epidemics of tomato yellow leaf curl disease (Garcia-Andres et al. 2006). In contrast, no susceptibility of $S$. nigrum to $P$. infestans was observed in the present study where a strain of the pathogen that was isolated from agricultural fields in southern Sweden was used. Similarly, we have not observed infected $S$. nigrum plants in over 50 field visits over the 
last few years, even when grown close to heavily infected potato plants. The results, taken together with the lack of naturally occurring infections, suggest that $S$. nigrum is not a reservoir of the pathogen in southern Sweden; hence, this species is probably not important in the epidemiology of late blight.

Large variation of $\boldsymbol{P}$. infestans resistance in $\boldsymbol{S}$. dulcamara. The $P$. infestans resistance varied widely among $S$. dulcamara genotypes; $S$. dulcamara siblings showed different resistance levels to $P$. infestans $\left(\mathrm{R}, \mathrm{R}^{\mathrm{N}}, \mathrm{S}^{\mathrm{L}}\right.$, and $\left.\mathrm{S}\right)$. These resistance types showed significantly different lesion areas and $P$. infestans biomass, which may reflect variable resistance mechanisms of $P$. infestans interactions with $S$. dulcamara. The phenotype $\mathrm{R}$ shows resistance without any macroscopic signs while the $\mathrm{R}^{\mathrm{N}}$ phenotype is associated with a hypersensitivity response triggered by $P$. infestans infection, suggesting differences in efficacy of each resistance mechanisms against the pathogen in S. dulcamara. Genetic mapping of two loci with putative $S$. dulcamara resistance genes, Rpi-dlcl and Rpi-dlc2 against $P$. infestans has been carried out (Golas et al. 2010b, 2013). Our results of the expanded populations in 2013 and 2014 indicate that S. dulcamara contain several different unlinked sources of resistance. Additionally, S. dulcamara genotypes showed variable resistance reactions across the years, such as a reduced within-population difference in resistance between Geneticum and Lomma2 populations in 2014. This might indicate an environmental influence and plasticity of the resistance trait under natural conditions. For example, it was reported that, in $S$. dulcamara, induced resistance against herbivory can protect the plant from later herbivory (Viswanathan et al. 2005; Westphal et al. 1991); this may indicate the potential of this species to induce $P$. infestans resistance following environmental and biological stresses in natural conditions.

All the $S$. dulcamara populations investigated in this study have genotypes with contrasting resistance phenotypes. However, a previous study indicated that it was rare to find $S$. dulcamara genotypes susceptible to $P$. infestans (Golas et al. 2010b). Only 3 out of 15 wild Solanum collection sites, from 12 countries, contained both susceptible and resistant genotypes (Golas et al. 2010b). Therefore, considering the geographical proximity of the collection sites in southern Sweden, the variation in P. infestans resistance found within the populations and within sibling genotypes of $S$. dulcamara from Sweden was surprising. This is also in line with the fact that the resistance variation explained at the sibling level was larger than the variation attributed at the population level.

The correlation analysis between plant performance parameters and lesion area showed that resistant $S$. dulcamara genotypes produce large number of branches and no other significant differences were found. Activated plant defense against pathogens can lead to fitness costs hence reduced plant performance or growth (Brown and Rant 2013; Vos 2013; Zavala et al. 2004). However, the result in this study show that the resistant $S$. dulcamara genotypes produced larger number of branches, suggesting no evidence for a direct fitness cost of resistance in this species. While we cannot exclude a cost of resistance, it is conceivable that a low cost of possessing this trait in the absence of the pathogen could contribute to maintenance of a polymorphism in the resistance trait (MacQueen and Bergelson 2016).

The mean lesion area in the susceptible (S) phenotype in the detached leaf assay on chamber grown plants did not differ significantly between $S$. dulcamara and $S$. physalifolium genotypes. However, in 2013, when $S$. dulcamara was grown in an adjacent field, natural infection was observed only in S. physalifolium plants. Moreover, despite the yearly presence of symptoms in the area, there was no confirmed symptom of infection in S. dulcamara leaves. Consistent with this, it has been reported that $S$. dulcamara was hardly ever naturally infected with $P$. infestans in the Netherlands

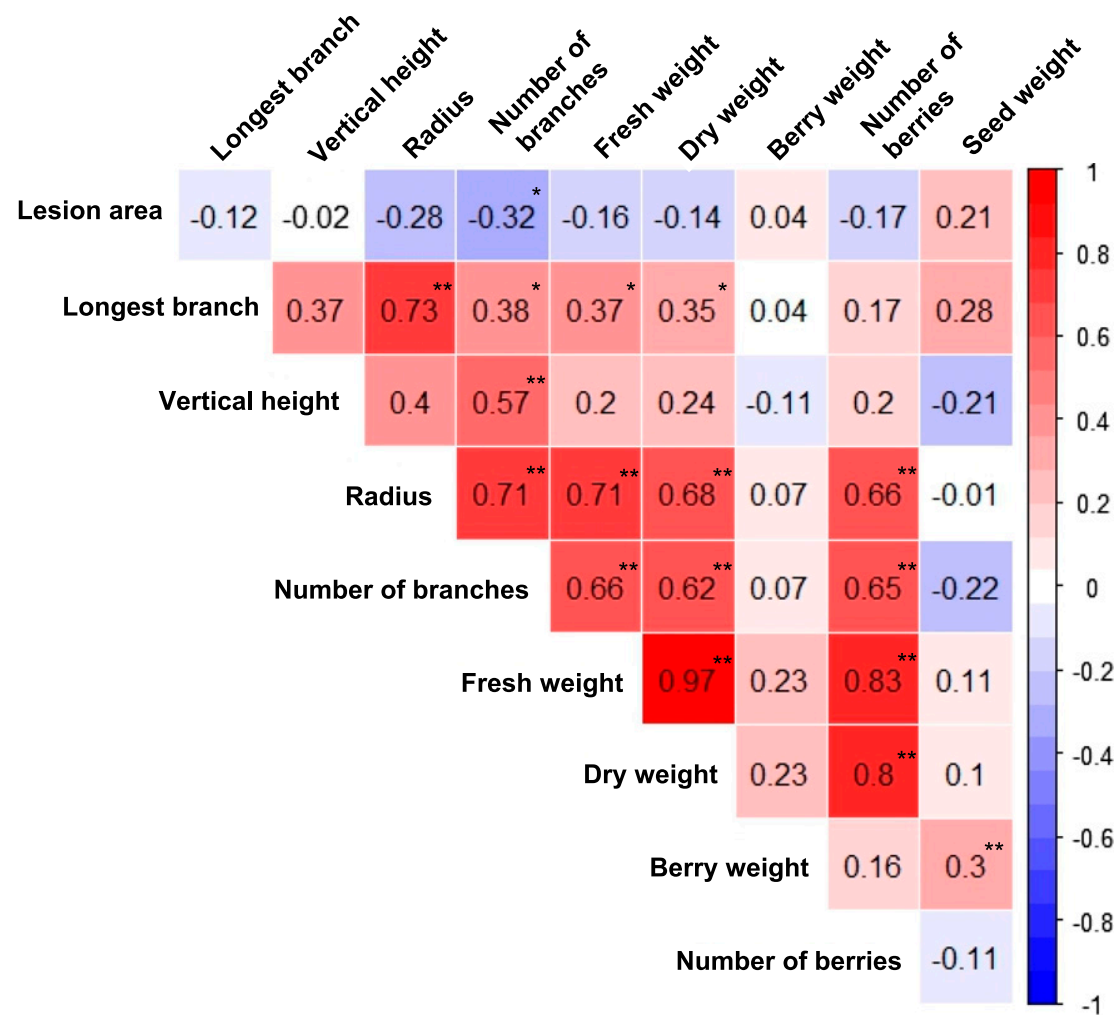

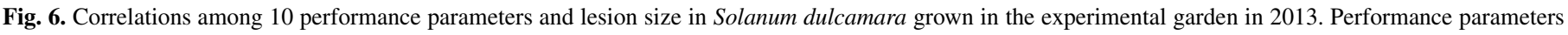

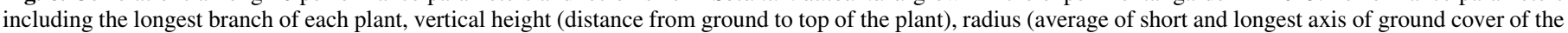

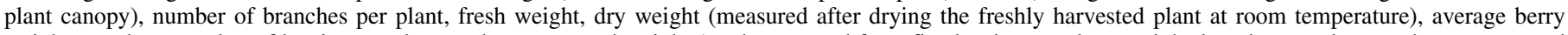

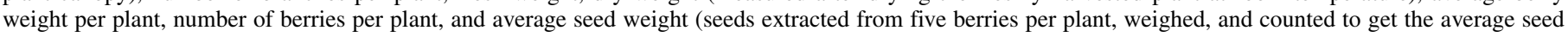

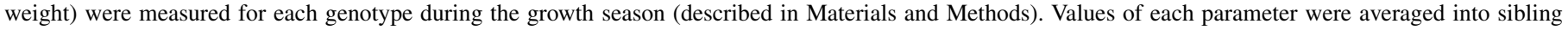
groups and correlations between parameters were tested using Spearman correlation. $* *, P<0.01 ;$ and $*, P<0.05$. 
(Flier et al. 2003) or in Ireland (Cooke et al. 2002). Therefore, we conclude that at least leaves of S. dulcamara have a limited role in the epidemiology of late blight in Sweden.

Conclusion. We found that all $S$. physalifolium genotypes were susceptible to $P$. infestans and that natural infection and shedding of blighted leaves opens for an epidemiological role for this species in late blight disease management in southern Sweden. S. nigrum was resistant to the $P$. infestans strain used and no infections by natural populations of the pathogen were detected of $S$. nigrum genotypes which may highlight the robustness of this species resistance to $P$. infestans. The large resistance variation against $P$. infestans observed among $S$. dulcamara genotypes in detached leaf assays, even within the populations and within sibling groups, indicates diverse resistance in this species. The role of $S$. dulcamara leaves in the spreading of late blight disease is probably small since no natural infection of plants was observed. However, genotypes with contrasting resistance reactions can potentially be useful to unravel new mechanisms of $P$. infestans resistance.

\section{ACKNOWLEDGMENTS}

We thank E. Alexandersson and A. T. S. Nilsson for discussions, as well as all other Resistance Biology group members.

\section{LITERATURE CITED}

Ali, A., Moushib, L. I., Lenman, M., Levander, F., Olsson, K., Carlson-Nilson, U., Zoteyeva, N., Liljeroth, E., and Andreasson, E. 2012. Paranoid potato: Phytophthora-resistant genotype shows constitutively activated defense. Plant Signal. Behav. 7:400-408.

Andersson, B., Johansson, M., and Jonsson, B. 2003. First report of Solanum physalifolium as a host plant for Phytophthora infestans in Sweden. Plant Dis. 87:1538.

Bengtsson, T., Holefors, A., Witzell, J., Andreasson, E., and Liljeroth, E. 2014a. Activation of defence responses to Phytophthora infestans in potato by BABA. Plant Pathol. 63:193-202.

Bengtsson, T., Weighill, D., Proux-Wera, E., Levander, F., Resjo, S., Burra, D. D., Moushib, L. I., Hedley, P. E., Liljeroth, E., Jacobson, D., Alexandersson, E., and Andreasson, E. 2014b. Proteomics and transcriptomics of the BABA-induced resistance response in potato using a novel functional annotation approach. BMC Genomics 15:315.

Brown, J. K., and Rant, J. C. 2013. Fitness costs and trade-offs of disease resistance and their consequences for breeding arable crops. Plant Pathol. 62(Suppl. 1).

Brown, J. K. M., and Tellier, A. 2011. Plant-parasite coevolution: Bridging the gap between genetics and ecology. Annu. Rev. Phytopathol. 49: 345-367.

Burdon, J. J., and Thrall, P. H. 2008. Pathogen evolution across the agroecological interface: Implications for disease management. Evol. Appl. 1: $57-65$.

Colon, I., Eijlander, R., Budding, D., Van Ijzendoorn, M., Pieters, M., and Hoogendoorn, J. 1992. Resistance to potato late blight (Phytophthora infestans (Mont.) de Bary) in Solanum nigrum, S. villosum and their sexual hybrids with $S$. tuberosum and $S$. demissum. Euphytica 66:55-64.

Cooke, L. R., Carlisle, D. J., Wilson, D. G., and Deahl, K. L. 2002. Natural occurrence of Phytophthora infestans on woody nightshade (Solanum dulcamara) in Ireland. Plant Pathol. 51:392.

Dawood, T., Rieu, I., Wolters-Arts, M., Derksen, E. B., Mariani, C., and Visser, E. J. W. 2014. Rapid flooding-induced adventitious root development from preformed primordia in Solanum dulcamara. AoB Plants 6:plt058.

Elphinstone, J. G., Stanford, H. M., and Stead, D. E. 1998. Detection of Ralstonia solanacearum in potato tubers, Solanum dulcamara and associated irrigation water. Pages 133-139 in: Bacterial Wilt Disease: Molecular and Ecological Aspects. P. Prior, C. Allen, and J. Elphinstone, eds. Springer, Berlin, Heidelberg.

Eriksson, D., Carlson-Nilsson, U., Ortíz, R., and Andreasson, E. 2016. Overview and breeding strategies of table potato production in Sweden and the Fennoscandian Region. Potato Research 1-16.

Flier, W. G., van den Bosch, G. B. M., and Turkensteen, L. J. 2003. Epidemiological importance of Solanum sisymbriifolium, S. nigrum and S. dulcamara as alternative hosts for Phytophthora infestans. Plant Pathol. 52:595-603.

Frades, I., Abreha, K. B., Proux-Wéra, E., Lankinen, Å., Andreasson, E., and Alexandersson, E. 2015. A novel workflow correlating RNA-seq data to Phytophthora infestans resistance levels in wild Solanum species and potato clones. Front. Plant Sci. 6:718.
Fukuoka, S., Saka, N., Mizukami, Y., Koga, H., Yamanouchi, U., Yoshioka, Y., Hayashi, N., Ebana, K., Mizobuchi, R., and Yano, M. 2015. Gene pyramiding enhances durable blast disease resistance in rice. Sci. Rep. 5:7773.

Garcia-Andres, S., Monci, F., Navas-Castillo, J., and Moriones, E. 2006. Begomovirus genetic diversity in the native plant reservoir Solanum nigrum: Evidence for the presence of a new virus species of recombinant nature. Virology 350:433-442.

Golas, T. M., Feron, R. M. C., van den Berg, R. G., van der Weerden, G. M., Mariani, C., and Allefs, J. J. H. M. 2010a. Genetic structure of European accessions of Solanum dulcamara L. (Solanaceae). Plant Syst. Evol. 285: $103-110$

Golas, T. M., Sikkema, A., Gros, J., Feron, R. M. C., van den Berg, R. G., van der Weerden, G. M., Mariani, C., and Allefs, J. J. H. M. 2010b. Identification of a resistance gene Rpi-dlcl to Phytophthora infestans in European accessions of Solanum dulcamara. Theor. Appl. Genet. 120:797-808.

Golas, T. M., van de Geest, H., Gros, J., Sikkema, A., D’Agostino, N., Nap, J. P., Mariani, C., Allefs, J. J., and Rieu, I. 2013. Comparative next-generation mapping of the Phytophthora infestans resistance gene Rpi-dlc2 in a European accession of Solanum dulcamara. Theor. Appl. Gen. 126:59-68.

Gronberg, L., Andersson, B., and Yuen, J. 2012. Can weed hosts increase aggressiveness of Phytophthora infestans on potato? Phytopathology 102: 429-433.

Gyetvai, G. M. 2010. Structural and functional characterization of R1homologous genes. Ph.D. thesis. Mathematisch-Naturwissen schaftlichen Fakultät, Universität Köln, Germany.

Haas, B. J., Kamoun, S., Zody, M. C., Jiang, R. H., Handsaker, R. E., Cano, L. M., Grabherr, M., Kodira, C. D., Raffaele, S., Torto-Alalibo, T., Bozkurt, T. O., Ah-Fong, A. M., Alvarado, L., Anderson, V. L., Armstrong, M. R., Avrova, A., Baxter, L., Beynon, J., Boevink, P. C., Bollmann, S. R., Bos, J. I., Bulone, V., Cai, G., Cakir, C., Carrington, J. C., Chawner, M., Conti, L., Costanzo, S., Ewan, R., Fahlgren, N., Fischbach, M. A., Fugelstad, J., Gilroy, E. M., Gnerre, S., Green, P. J., Grenville-Briggs, L. J., Griffith, J., Grunwald, N. J., Horn, K., Horner, N. R., Hu, C. H., Huitema, E., Jeong, D. H., Jones, A. M., Jones, J. D., Jones, R. W., Karlsson, E. K., Kunjeti, S. G., Lamour, K., Liu, Z., Ma, L., Maclean, D., Chibucos, M. C., McDonald, H., McWalters, J., Meijer, H. J., Morgan, W., Morris, P. F., Munro, C. A., O’Neill, K., Ospina-Giraldo, M., Pinzon, A., Pritchard, L., Ramsahoye, B., Ren, Q., Restrepo, S., Roy, S., Sadanandom, A., Savidor, A., Schornack, S., Schwartz, D. C., Schumann, U. D., Schwessinger, B., Seyer, L., Sharpe, T., Silvar, C., Song, J., Studholme, D. J., Sykes, S., Thines, M., van de Vondervoort, P. J., Phuntumart, V., Wawra, S., Weide, R., Win, J., Young, C., Zhou, S., Fry, W., Meyers, B. C., van West, P., Ristaino, J., Govers, F., Birch, P. R., Whisson, S. C., Judelson, H. S., and Nusbaum, C. 2009. Genome sequence and analysis of the Irish potato famine pathogen Phytophthora infestans. Nature 461:393-398.

Haverkort, A. J., Struik, P. C., Visser, R. G. F., and Jacobsen, E. 2009. Applied biotechnology to combat late blight in potato caused by Phytophthora infestans. Potato Res. 52:249-264.

Lankinen, A., Abreha, K. B., Alexandersson, E., Andersson, S., and Andreasson, E. 2016. Nongenetic inheritance of induced resistance in a wild annual plant. Phytopathology 106:877-883.

Lebecka, R. 2008. Host-pathogen interaction between Phytophthora infestans and Solanum nigrum, S. villosum, and S. scabrum. Eur. J. Plant Pathol. 120: 233-240.

Lebecka, R. 2009. Inheritance of resistance in Solanum nigrum to Phytophthora infestans. Eur. J. Plant Pathol. 124:345-348.

MacQueen, A., and Bergelson, J. 2016. Modulation of R-gene expression across environments. J. Exp. Bot. 67:2093-2105.

Mossberg, B., and Stenberg, L. 2003. Den Nya Nordiska Floran. Wahlstrom \& Widstrand, Stockholm.

Moushib, L., Witzell, J., Lenman, M., Liljeroth, E., and Andreasson, E. 2013. Sugar beet extract induces defence against Phytophthora infestans in potato plants. Eur. J. Plant Pathol. 136:261-271.

Nelson, S. C., and Campbell, C. L. 1993. Disease progress, defoliation, and spatial pattern in a multiple-pathogen disease complex on white clover. Phytopathology 83:419-429.

Palmgren, M. G., Edenbrandt, A. K., Vedel, S. E., Andersen, M. M., Landes, X., Osterberg, J. T., Falhof, J., Olsen, L. I., Christensen, S. B., Sandoe, P., Gamborg, C., Kappel, K., Thorsen, B. J., and Pagh, P. 2015. Are we ready for back-to-nature crop breeding? Trends Plant Sci. 20:155-164.

Persson, P. 1998. Successful eradication of Ralstonia solanacearum from Sweden1. EPPO Bull. 28:113-119.

Pohlert, T. 2015. PMCMR: Calculate pairwise multiple comparisons of mean rank sums. https://cran.r-project.org/web/packages/PMCMR/PMCMR.pdf

Rietman, H., Bijsterbosch, G., Cano, L. M., Lee, H. R., Vossen, J. H., Jacobsen, E., Visser, R. G. F., Kamoun, S., and Vleeshouwers, V. G. A. A. 2012. Qualitative and quantitative late blight resistance in the potato cultivar Sarpo Mira is determined by the perception of five distinct RXLR effectors. Mol. Plant-Microbe Interact. 25:910-919. 
Rodewald, J., and Trognitz, B. 2013. Solanum resistance genes against Phytophthora infestans and their corresponding avirulence genes. Mol. Plant Pathol. 14:740-757.

Sharma, B. P., Forbes, G. A., Manandhar, H. K., Shrestha, S. M., and Thapa, R. B. 2013. Determination of resistance to Phytophthora infestans on potato plants in field, laboratory and greenhouse conditions. J. Agric. Sci. 5:5.

SPSS. 2016. IBM Corp. Released 2016 IBM SPSS Statistics for Windows, Version 24.0. IBM Corp., Armonk, NY.

Viswanathan, D. V., Narwani, A. J. T., and Thaler, J. S. 2005. Specificity in induced plant responses shapes patterns of herbivore occurrence on Solanum dulcamara. Ecology 86:886-896.

Vleeshouwers, V. G. A. A., van Dooijeweert, W., Govers, F., Kamoun, S., and Colon, L. T. 2000. The hypersensitive response is associated with host and nonhost resistance to Phytophthora infestans. Planta 210: 853-864.

Vos, I. A. 2013. Costs and benefits of hormone-regulated plant defences. Plant Pathol. 62:43-55.

Wei, T. 2013. corrplot: Visualization of a correlation matrix. R package version 0.73. http://cran.r-project.org/web/packages/corrplot/index.html

Wenneker, M., Verdel, M. S. W., Groeneveld, R. M. W., Kempenaar, C., van Beuningen, A. R., and Janse, J. D. 1999. Ralstonia (Pseudomonas) solanacearum race 3 (biovar 2) in surface water and natural weed hosts: First report on stinging nettle (Urtica dioica). Eur. J. Plant Pathol. 105:307-315.

Westphal, E., Dreger, F., and Bronner, R. 1991. Induced resistance in Solanum dulcamara triggered by the gall mite Aceria-Cladophthirus (Acari, Eriophyoidea). Exp. Appl. Acarol. 12:111-118.

Widmark, A. K., Andersson, B., Cassel-Lundhagen, A., Sandstrom, M., and Yuen, J. E. 2007. Phytophthora infestans in a single field in southwest Sweden early in spring: Symptoms, spatial distribution and genotypic variation. Plant Pathol. 56:573-579.

Yuen, J. E., and Andersson, B. 2013. What is the evidence for sexual reproduction of Phytophthora infestans in Europe? Plant Pathol. 62:485-491.

Zavala, J. A., Patankar, A. G., Gase, K., and Baldwin, I. T. 2004. Constitutive and inducible trypsin proteinase inhibitor production incurs large fitness costs in Nicotiana attenuata. Proc. Natl. Acad. Sci. USA 101:1607-1612.

Zhan, J. S., Thrall, P. H., Papaix, J., Xie, L. H., and Burdon, J. J. 2015. Playing on a pathogen's weakness: Using evolution to guide sustainable plant disease control strategies. Annu. Rev. Phytopathol. 53:19-43.

Zhang, B., Yang, Y., Chen, T., Yu, W., Liu, T., Li, H., Fan, X., Ren, Y., Shen, D., Liu, L., Dou, D., and Chang, Y. 2012. Island cotton Gbve1 gene encoding a receptor-like protein confers resistance to both defoliating and non-defoliating isolates of Verticillium dahliae. PLoS One 7:e51091. 